\title{
Regenerative and fibrotic pathways in canine hepatic portosystemic shunt and portal vein hypoplasia, new models for clinical hepatocyte growth factor treatment
}

\author{
Bart Spee*1, Louis C Penning ${ }^{1}$, Ted SGAM van den Ingh ${ }^{2}$, Brigitte Arends ${ }^{1}$, \\ Jooske IJzer ${ }^{2}$, Frederik J van Sluijs ${ }^{1}$ and Jan Rothuizen ${ }^{1}$
}

Address: ${ }^{1}$ Department of Clinical Sciences of Companion Animals, Faculty of Veterinary Medicine, Utrecht University, Utrecht, The Netherlands and ${ }^{2}$ Department of Pathobiology, Faculty of Veterinary Medicine, Utrecht University, Utrecht, The Netherlands

Email: Bart Spee* - b.spee@vet.uu.nl; Louis C Penning - l.c.penning@vet.uu.nl; Ted SGAM van den Ingh - t.s.g.a.m.vandenIngh@wanadoo.nl; Brigitte Arends - b.arends@vet.uu.nl; Jooske IJzer - j.ijzer@vet.uu.nl; Frederik J van Sluijs - f.j.vansluijs@vet.uu.nl; Jan Rothuizen - j.rothuizen@vet.uu.nl

* Corresponding author

Published: 07 December 2005

Comparative Hepatology 2005, 4:7 doi:10.1186/1476-5926-4-7
Received: 10 February 2005

Accepted: 07 December 2005

This article is available from: http://www.comparative-hepatology.com/content/4/1/7

(c) 2005 Spee et al; licensee BioMed Central Ltd.

This is an Open Access article distributed under the terms of the Creative Commons Attribution License (http://creativecommons.org/licenses/by/2.0), which permits unrestricted use, distribution, and reproduction in any medium, provided the original work is properly cited.

\begin{abstract}
Background: We analyzed two spontaneous dog diseases characterized by subnormal portal perfusion and reduced liver growth: (i) congenital portosystemic shunts (CPSS) without fibrosis and (ii) primary portal vein hypoplasia (PPVH), a disease associated with fibrosis. These pathologies, that lack inflammation or cholestasis, may represent simplified models to study liver growth and fibrosis. To investigate the possible use of those models for hepatocyte growth factor (HGF) treatment, we studied the functionality of HGF signaling in CPSS and PPVH dogs and compared this to aged-matched healthy controls.

Results: We used quantitative real-time polymerase chain reaction (Q-PCR) to analyze the mRNA expression of HGF, transforming growth factor $\beta$ I (TGF- $\beta I$ ), and relevant mediators in liver biopsies from cases with CPSS or PPVH, in comparison with healthy control dogs. CPSS and PPVH were associated with a decrease in mRNA expression of HGF and of MET proto-oncogene (cMET). Western blot analysis confirmed the Q-PCR results and showed that intracellular signaling components (protein kinase B/Akt, ERKI/2, and STAT3) were functional. The TGF- $\beta$ I mRNA levels were unchanged in CPSS whereas there was a 2-fold increase in PPVH indicating an active TGF- $\beta$ I pathway, consistent with the observation of fibrosis seen in PPVH. Western blots on TGF$\beta I$ and phosphorylated Smad2 confirmed an activated pro-fibrotic pathway in PPVH. Furthermore, Q-PCR showed an increase in the amount of collagen I present in PPVH compared to CPSS and control, which was confirmed by Western blot analysis.
\end{abstract}

Conclusion: The pathophysiological differences between CPSS and PPVH can adequately be explained by the Q-PCR measurements and Western blots. Although c-MET levels were reduced, downstream signaling seemed to be functional and provides a rational for HGF-supplementation in controlled studies with CPSS and PPVH. Furthermore both diseases may serve as simplified models for comparison with more complex chronic inflammatory diseases and cirrhosis. 


\section{Background}

Chronic liver disease is characterized by decreased regeneration of hepatocytes and increased formation of fibrous tissue. These characteristics may be the sequel of various chronic processes such as cholestasis, viral infections, toxin exposure, and metabolic disorders. Dogs have complex liver diseases such as hepatitis and cirrhosis which are highly comparable with the human counterparts. Moreover, coding sequences of dogs proved highly homologous to the human sequences [1], especially compared to the rodent genome. Thus, dogs may fulfill a role as a spontaneous animal model in between toxin-induced or surgical models in rodents, and spontaneous diseases in man. The complex interplay of many factors active in chronic liver disease makes it difficult to unravel the roles of different individual pathogenetic pathways. Dogs display liver diseases, which are potentially valuable models to compare complex with simple pathologic entities.

We have chosen these two congenital dog diseases for comparative analysis of liver growth/regeneration, fibrosis, and hepatic homeostasis: congenital portosystemic shunt (CPSS) and primary portal vein hypoplasia (PPVH). CPSS is characterized by an abnormal single large communication between the portal vein and a major systemic vein (cava or azygos). This results in the virtual absence of portal vein perfusion to the liver from birth onwards. Liver growth remains nearly absent but there is essentially no liver pathology $[2,3]$. PPVH is a developmental abnormality in which the terminal vein branches are not or only partially present and, in most cases, in combination with congenital portal fibrosis, but without inflammation [4]. PPVH is associated with portal hypertension and reduced liver growth. Thus, these two congenital diseases represent relatively simple models for reduced liver growth associated with fibrosis (PPVH) or without fibrosis (CPSS). Both diseases have a decrease in liver growth due to differences in portal perfusion which results in a massive reduction of liver size.

Because hepatocyte growth factor (HGF) is one of the most important genes involved in liver growth/regeneration [5-7], abnormal expression of HGF could play a major role in the decreased liver size in CPSS or PPVH. Therefore, treatment of dogs with HGF could be a possible therapeutic approach. A pre-requisite for treatment is that HGF signaling components are unaffected in those dogs. Consequently, we focused on measuring gene products involved in signaling of HGF and counteracting transforming growth factor $\beta 1$ (TGF- $\beta 1$ ). All biological responses induced by HGF are elicited by binding to its receptor, a transmembrane tyrosine kinase encoded by the MET proto-oncogene (c-MET). The signaling cascade triggered by HGF begins with phosphorylation of the receptor and is mediated by concomitant activation of different cytoplasmic effectors that bind to the same multifunctional binding site. The c-MET mediated response includes two key pathways involved in cell survival and mitogenesis [8]. The first; protein kinase $\mathrm{B}$ (PKB/Akt) is activated by phosphoinositide 3-kinase (PI3K) and elicits cell survival $[9,10]$. The second; ERK1/2 (also known as $\mathrm{p} 42 / 44 \mathrm{MAPK})$, a member of the mitogen-activated protein (MAP) kinase family, is activated by the RAS-RAFMEK pathway and is responsible for mitogenesis [11]. A third response of HGF is the branching morphogenesis which next to the PKB and ERK pathways requires involvement of the signal transducer and activator of transcription (STAT) 3 pathway [12].

It is well established that an increase of TGF- $\beta 1$ in liver promotes the formation of extracellular matrix (ECM) components and suppresses hepatocyte proliferation $[13,14]$. Prolonged overexpression of TGF- $\beta 1$ in nonparenchymal cells causes hepatic fibrosis in humans and experimental animals. In several fibrosis models, fibrotic lesions are associated with an increase in collagens and TGF- $\beta 1$ mRNAs [15]. The intracellular pathway that is activated by TGF- $\beta 1$ receptors is mediated by Smads. Smad2 is activated via carboxy-terminal phosphorylation by TGF- $\beta 1$ type I receptor kinases. When bound with coSmads, they act as TGF- $\beta 1$-induced transcriptional activators of target genes [16].

Cell homeostasis is the result of balance between cell death, cell proliferation, and growth-arrest. Therefore we investigated expression levels of pro-apoptotic Fas ligand and caspase-3, anti-apoptotic Bcl-2 [17], cell-cycle stimulating TGF $\alpha$, and cell-cycle inhibitor p27kip. All of these gene-products are regulated directly or indirectly by $\mathrm{PKB}$ [9].

The present study was designed to describe the differential gene-expression of the above indicated crucial pathways involved in growth/regeneration, fibrosis, and cellular homeostasis in liver tissues of dogs with CPSS (reduced growth/regeneration without fibrosis) and $\mathrm{PPVH}$ (reduced growth/regeneration and fibrosis) in comparison with healthy animals. These simple congenital dog models may be used to unravel the roles of different gene products in those pathways. These well-defined large animal models are intended to serve as the first spontaneous liver diseases to investigate novel regenerative/antifibrotic therapies, such as HGF treatment. This study may also serve as a basis for future comparison with more complex diseases like chronic hepatitis and cirrhosis.

\section{Results \\ Histological grading of fibrosis}

No fibrosis was seen in liver biopsies of CPSS dogs. In the PPVH dogs histological examination revealed slight portal 

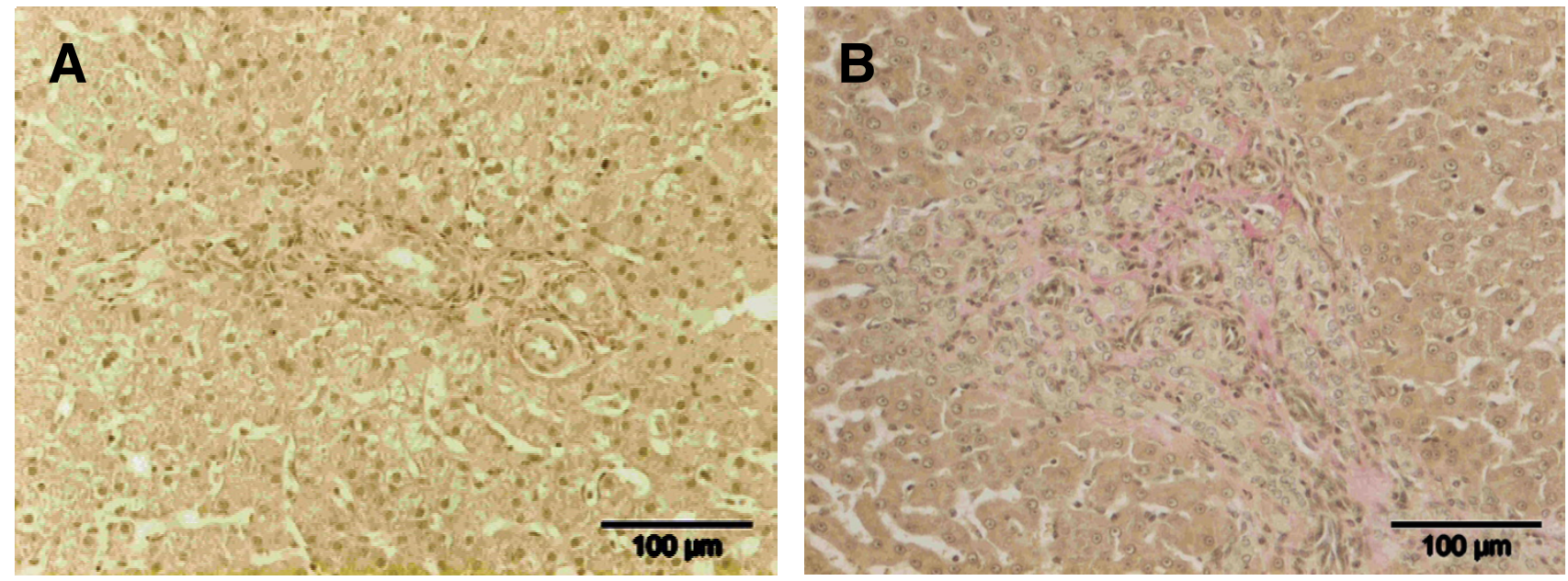

Figure I

Histological grading of fibrosis. (A) CPSS, Portal area without recognizable portal vein and arteriolar proliferation. Van Gieson stain. (B) PPVH, Markedly enlarged portal area with fibrosis and extensive arteriolar and ductular proliferation. Van Gieson stain.

fibrosis in one dog, slight to moderate portal fibrosis associated with slight to moderate centrolobular fibrosis in four dogs, and marked portal fibrosis with biliary proliferation in three dogs. The control dogs showed a normal liver without fibrosis. Examples of histological examination of CPSS and PPVH are included as Figures 1A and 1B, respectively.

\section{HGF/c-MET signaling pathway involved in regeneration and growth}

One of the main in vivo events during regeneration and growth is the signaling via phosphorylation of the HGF receptor c-MET. Q-PCR analysis revealed that HGF mRNA levels in both CPSS and PPVH were decreased three-fold in comparison with healthy dogs (Figure 2). Moreover, the c-MET levels in CPSS and PPVH were significantly decreased (two- and three-fold, respectively). The levels of the mRNAs for TGF $\alpha$ (proliferation) were decreased sixfold in both CPSS and PPVH. The serine-protease HGF activator mRNA was doubled in dogs with CPSS. In contrast, it was halved in dogs with PPVH. Although not significantly in dogs with CPSS, the cell-cycle inhibitor p27kip mRNA was decreased in both conditions.

\section{TGF- $\beta$ I cascade signaling pathway involved in fibrosis}

The fibrosis signaling pathway is activated through bindings of the active TGF- $\beta 1$ dimer to the heteromeric type-I and type-II serine/threonine receptor kinases. As shown in Figure 3, TGF- $\beta 1$ mRNA levels were increased two-fold in dogs with PPVH, whereas the levels in dogs with CPSS were not changed significantly. The receptor type-I, was induced in both liver diseases but only significantly in
PPVH. Receptor type-II was increased in both CPSS and PPVH (4- and 5-fold, respectively), indicating an increased binding capacity. One of the proteolytic enzymes involved in activation of TGF- $\beta 1$ is urokinase plasminogen activator (uPA). The uPA mRNA level was decreased two-fold in dogs with CPSS and, in contrast, doubled in dogs with PPVH.

\section{Gene-expression of apoptosis-related signaling proteins and hypoxia induced factor}

We measured three well-known basic apoptotic components of which two are pro-apoptotic (caspase-3 and Fas ligand) and one is anti-apoptotic ( $\mathrm{Bcl}-2)$. Figure 4 shows that pro-apoptotic mediator Fas ligand was severely inhibited in both dogs with CPSS and in dogs with PPVH (14and 8-fold, respectively). Moreover, caspase-3 was halved in both CPSS and PPVH. On the other hand, no induction of the anti-apoptotic Bcl-2 was seen in dogs with CPSS, whereas Bcl-2 in dogs with PPVH was doubled. The mechanisms underlying progressive fibrosis are unknown, but fibrosis and hypoxia could have been a fibrogenic stimulus. Hypoxia coordinately up-regulates matrix production and hypoxia induced factor 1 alpha (HIF1 $\alpha$ ) [18]. These direct hypoxic effects on the expression of genes involved in fibrogenesis was shown in our dogs with PPVH which indeed had elevated levels of HIF1 $\alpha$.

\section{Gene-expression of extracellular matrix gene products}

The analysis of ECM expression was performed on three collagens (I, III and IV) and one glycoprotein (fibronectin). Interstitial collagens types I and III are the most commonly found collagens, collagen type IV is a basal 


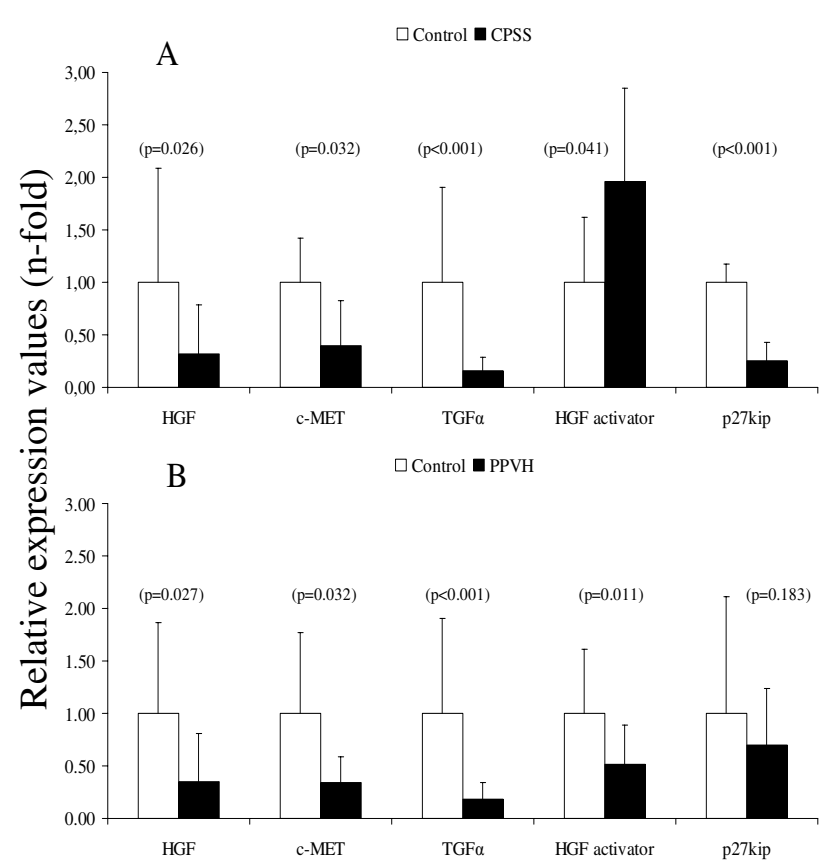

Figure 2

Quantitative real-time PCR of genes involved in regeneration and growth. Representative data of mRNA levels of congenital portosystemic shunt (CPSS, $n=1$ l dogs) is shown in (A). Representative data of mRNA levels of primary portal vein hypoplasia (PPVH, $n=8$ dogs) is shown in (B). Data represent mean $\pm 2 S D$.

membrane collagen. In Figure 5, collagen I was shown to be significantly increased in PPVH (two-fold), whereas CPSS was unchanged. Collagen III and IV were not significantly changed in both groups. Fibronectin showed to be halved in the CPSS group where PPVH remained normal.

Western blot analysis of HGF, c-MET, PKB, STAT3, ERK, TGF- $\beta$ I, Smad2, Collagen I, and Caspase-3

PKB plays a pivotal role in liver regeneration and growth upon activation of the c-MET-HGF signaling pathway [10]. Western blot analysis of HGF showed an immunoreactive band at $82 \mathrm{kDa}$ with no apparent quantitative differences (Figure 6A). Non-phosphorylated c-MET was detected in all samples, where it was present as an immunoreactive band of $145 \mathrm{kDa}$. Results showed a decrease in the amount of c-MET in both diseases. On the other hand, the anti-phosphorylated c-MET antibody showed an immunoreactive band in all samples with no apparent quantitative differences. Non-phosphorylated PKB was detected in all samples, where it was present as a single band of $60 \mathrm{kDa}$. The anti-phosphorylated PKB antibody showed an immunoreactive band in all samples. Two immunoreactive bands at 42 and $44 \mathrm{kDa}$ representing the MAP kinase ERK1/2 showed to be equally present at the

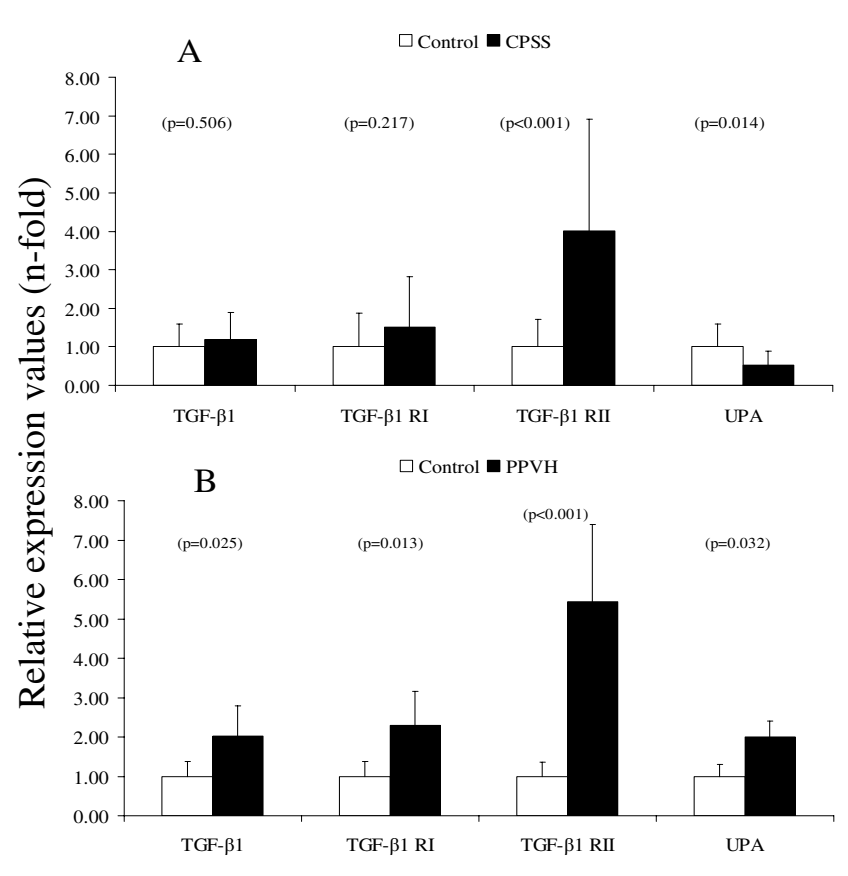

Figure 3

Quantitative real-time PCR of genes involved in

fibrosis. Representative data of mRNA levels of congenital portosystemic shunt (CPSS, $n=1$ I dogs) is shown in (A). Representative data of mRNA levels of primary portal vein hypoplasia (PPVH, $n=8$ dogs) is shown in (B). Data represent mean $\pm 2 S D$.

protein level between the diseased groups and healthy controls. Interestingly, this also applied for the phosphorylated form where no apparent quantitative differences were found. The $80 \mathrm{kDa}$ STAT3 protein showed a similar result with no apparent quantitative differences in the non-phosphorylated form; however, the STAT3 protein seemed to be somewhat less phosphorylated at the serine 727 residue in the PPVH group. TGF- $\beta 1$ exerts its actions through complex intracellular signaling pathways. All downstream signaling routes following binding of an active TGF- $\beta 1$ to its receptors type-I and II elicit phosphorylation of Smad2. TGF- $\beta 1$ was seen in all diseases as a single band of $25 \mathrm{kDa}$ under non-denaturing conditions (Figure 6B). Interestingly, the amount of TGF- $\beta 1$ was induced in PPVH compared to CPSS and controls. Nonphosphorylated Smad 2 was detected in all samples, where it was present as a single band of $58 \mathrm{kDa}$, with no apparent changes in quantity. Also interestingly, the anti-phosphorylated Smad 2 antibody showed a slight band in CPSS whereas in PPVH a phosphorylated Smad2 is clearly present. Moreover, anti-collagen I showed an increase in the amount of protein in PPVH compared to CPSS and healthy controls, all together emphasizing the differences in fibrosis between CPSS and PPVH. Although reduced in the CPSS and PPVH group, inactive or uncleaved caspase- 
3 was detected in all samples (Figure 6C), where it was present as a single band of $34 \mathrm{kDa}$. Finally, the processed forms of 20 and $13 \mathrm{kDa}$ showed to be increased in CPSS and PPVH towards healthy controls.

\section{Discussion}

In order to analyze the possibility of growth factor therapy, two congenital canine liver diseases were molecularly dissected. The expression of a total of 17 gene products involved in liver growth/regeneration, fibrosis, ECM, and cellular homeostasis was measured and normalized to the average amount of two reference genes (Q-PCR). Western blot analysis confirmed the quantitative mRNA results and, furthermore, showed activated pathways. These two independent techniques provided insight into the effects of portal venous hypoperfusion in two canine hepatic diseases; congenital portosystemic shunt (CPSS) without fibrosis and primary portal vein hypoplasia $(\mathrm{PPVH})$ with fibrosis. Taken together, the obtained data provided insights in the feasibility for HGF-treatment.

The normalization performed in this study was obtained by averaging the amount of two different reference genes, glyceraldehyde-3-phosphate dehydrogenase (GAPDH) and hypoxanthine phosphoribosyl transferase (HPRT). No samples were more than 5 percent apart from the individual measured reference genes levels (data not shown). This normalization strategy, using the average amount of two reference genes, is taken as a prerequisite for accurate Q-PCR expression profiling which enables us to measure small expression differences and allows the study of their biological relevance [19].

It is well known that HGF plays an essential role in development [20] and regeneration of the liver, and increases hepatocyte viability. The found decrease in gene-expression of both HGF and its receptor agrees with the reduced liver size in these canine disorders. However, and in contrast to the c-MET levels which correlate nicely with the found protein levels, the amount of HGF mRNA does not seem to reflect protein levels. This can be contributed to HGF which can be a paracrine but also an endocrine factor. Extra-hepatic HGF could have been present in the pancreas or intestinal tract [21].

Although HGF and c-MET mRNA levels were decreased, downstream targets of this tyrosine cascade signaling pathway were still active. Downstream targets, such as Fas ligand and p27kip, were chosen as direct or indirect targets of the HGF-CMET-PI3K-PKB axis. Fas ligand transcription is regulated by FOXO (forkhead box, sub-group "O" transcription factors). Therefore, the decrease in Fas ligand can be explained by an active PKB which directly phosphorylates FOXO [22]. A similar result can be seen in the reduced levels of p27kip mRNA, as this is down-regu- lated at the gene-transcription level by active PKB [23]. Combined, this indicates that PKB is active in both diseases, which was confirmed by Western blot analysis. It remains to be seen whether other receptor tyrosine kinases (e.g., EGF receptor or insulin receptor) activate this pathway in these dogs [24]. Next to the activated PKB pathway, we have analyzed other c-MET mediated responses in CPSS and PPVH. ERK1/2 showed to be activated in both diseases to a similar level as the healthy controls. The significance of the slightly reduced phosphorylated STAT3 in PPVH, which is phosphorylated by HGF on serine 727 [25], needs to be further investigated. Taken together, the pathways which elicit all major biological functions of c-MET showed to be active in CPSS and PPVH.

Prolonged or overexpression of TGF- $\beta 1$ acts to suppress cell proliferation, and induces a deposition of ECM proteins, resulting in fibrosis in major organs such as liver $[26,27]$. We showed that in PPVH the TGF- $\beta 1$ pathway through Smad2 is activated, consistent with the fibrosis seen in PPVH. Measurements on fibrosis related gene products revealed no elevated activity of the TGF- $\beta 1$ pathway in CPSS. Gene expression levels related to the TGF- $\beta 1$ pathway, including its receptors, and the proteolytic activator of TGF- $\beta 1$ (uPA) were elevated in PPVH, thus indicating an active Smad pathway that could subsequently lead to fibrosis. Western blot analysis confirmed found TGF- $\beta 1$ levels. Measurements on collagen gene-expression, especially collagen I, confirm the current paradigm of TGF- $\beta 1$ signaling in fibrous tissues like PPVH [28]. Contrary, non-fibrotic CPSS did not show any alterations in collagen expression. The observation of phosphorylated Smad2 in healthy liver tissue showed that the phosphorylation of Smad2 is a dynamic process and has already been described in other publications $[29,30]$.

The expressions of the pro-apoptotic genes Fas ligand and caspase- 3 were clearly decreased. $\mathrm{Bcl}-2$ gene-expression was elevated two times in PPVH; but not in CPSS (Figure 4 ). Western blot analysis showed that the unprocessed form of caspase- 3 was present in lesser amount in CPSS and PPVH; however, the amount of processed or active bands compared to healthy control was higher in the diseases compared to healthy controls. This indicates that although the total amount of caspase- 3 is lower, there is more cleavage of the caspase- 3 to its active forms in the diseases, possibly leading to an increase in apoptosis.

Both HGF and TGF- $\beta 1$ need extracellular processing to become biologically active. The serine protease HGF activator is responsible for activation of proHGF [31]. Our studies revealed that HGF activator gene-expression was doubled in dogs with CPSS and halved in case of PPVH. This indicated an increased HGF activation in CPSS. 


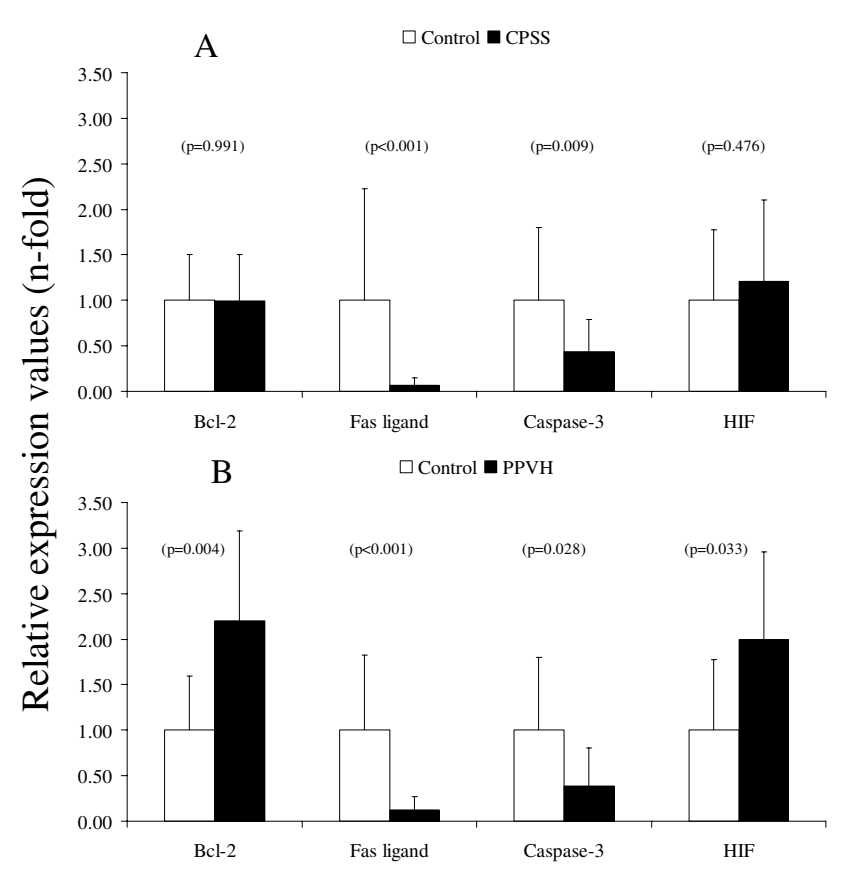

Figure 4

Quantitative real-time PCR of apoptosis genes and a hypoxia related gene. Representative data of mRNA levels of congenital portosystemic shunt (CPSS, $n=11$ dogs) is shown in (A). Representative data of mRNA levels of primary portal vein hypoplasia (PPVH, $n=8$ dogs) is shown in (B).

Data represent mean $\pm 2 S D$.

Although levels of HGF activator were reduced in PPVH, this does not necessarily indicate a lack of extracellular processing of HGF. Interestingly uPA, the activator of TGF- $\beta 1$, was expressed at an increased level in dogs with PPVH. This may, via active TGF- $\beta 1$-receptor interaction, indicate an activation of Smads and thus the formation of collagens.

Differential gene expression measurements on hepatic diseases have been performed in the past; nevertheless, little is known about levels of genes that play an important role in fibrosis. There have been measurements on cirrhosis in man and rat that indicate an up or down-regulated expression of several proteins [32]. Although these results might be significant in severe forms of fibrosis, these data depict an end-point of the disease whereas earlier stages may be more informative.

Regeneration with recombinant HGF has been achieved in rodent models of liver failure [33,34]. Moreover, besides its regenerative capacity, HGF is known to have an antifibrogenic effect $[35,36]$ and thus reduces or prevent fibrosis in PPVH. TGF- $\beta 1$ intervention to halt the progression of liver fibrosis and positively effect regeneration, has been applied successfully [37] even in cirrhosis [38]. The

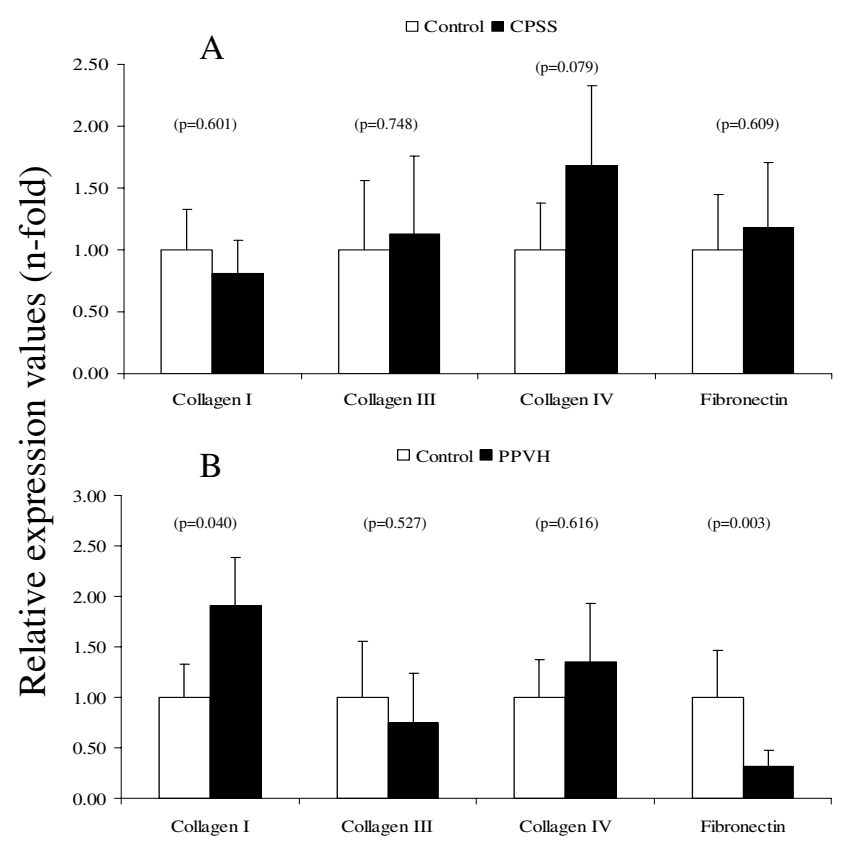

Figure 5

Quantitative real-time PCR of extracellular matrix gene products. Representative data of mRNA levels of congenital portosystemic shunt (CPSS, $n=1$ I dogs) is shown in $(A)$. Representative data of mRNA levels of primary portal vein hypoplasia (PPVH, $n=8$ dogs) is shown in (B). Data represent mean $\pm 2 \mathrm{SD}$.

measured gene products involved in fibrosis in PPVH make it a good spontaneous animal model to investigate new therapeutic strategies to influence the HGF and/or TGF- $\beta 1$ pathways in vivo. Furthermore, most fibrogenic models are induced by toxins such as dimethylnitrosamine $(\mathrm{DMN}), \mathrm{CCl}_{4}$, or thioacetamide [39]. The canine PPVH model is not drug-induced; therefore, may be better to compare with human diseases and thus fill the gap between induced rodent models and human diseases.

This study is the first to measure expression profiles of crucial pathways of liver growth/regeneration, fibrosis, and hepatic homeostasis in spontaneous canine liver diseases. The present findings in two diseases with relatively simple pathogenesis may also serve as basis for evaluation of more complex diseases like hepatitis and cirrhosis. Evaluation of such complex diseases in dogs is highly suitable for comparative studies on the roles of different pathways in the pathogenesis of liver diseases in man. Two further conclusions can be deduced from the data presented here. First, the pathophysiological differences between CPSS and PPVH can nicely be explained by the Q-PCR measurements and Western blots. Second, although c-MET levels were reduced, downstream signaling seemed to be functional and provides a rational background to design con- 
A

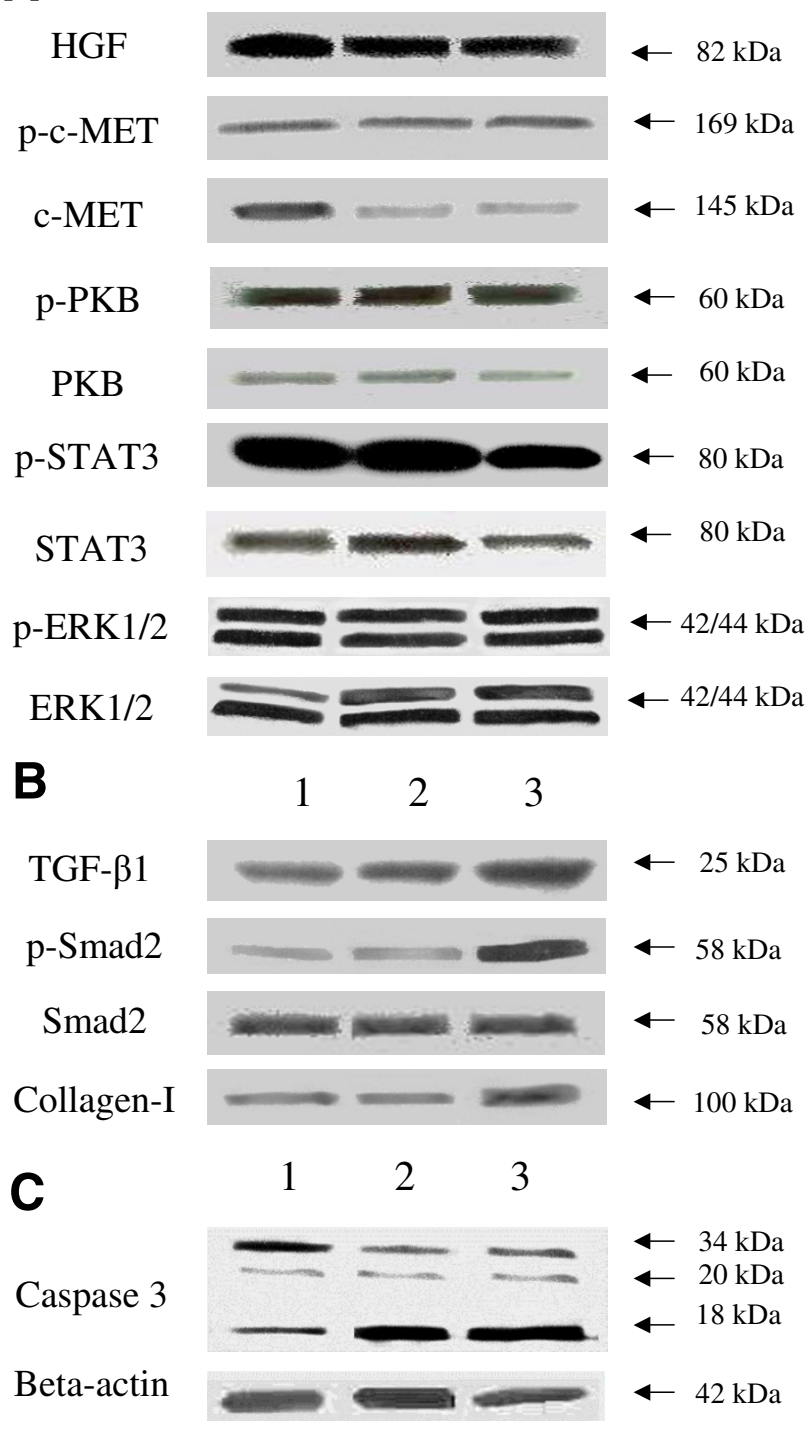

Figure 6

Western blot analysis of liver homogenates of controls, CPSS, and PPVH. Detection of HGF, c-MET, PKB, STAT, and ERK shown in (A), detection of the TGF- $\beta I$, Smad2, and Collagen I in (B), and detection of the Caspase3 protein, uncleaved/inactive $34 \mathrm{kDa}$, and cleaved/active products of $20 \mathrm{kDa}$ and $\mathrm{I} 3 \mathrm{kDa}$ in (C). Western blot analysis of liver homogenates $(n=6$ dogs per group, randomly chosen from original group). Lane samples: $I$ = control; 2 = congenital portosystemic shunt; 3 = primary portal vein hypoplasia.

trolled studies for HGF-supplementation in CPSS and PPVH.

\section{Methods \\ Animals}

All samples are obtained from different dog breeds appearing in the clinic with spontaneous diseases. Sam- ples were randomly chosen and aimed to encompass different dog-breeds and both sexes in each group. The procedures were approved by the Ethical Committee as required under Dutch legislation.

\section{Groups}

The congenital portosystemic shunt ( $\mathrm{n}=11 \mathrm{dogs})$ and primary portal vein hypoplasia group ( $\mathrm{n}=8 \mathrm{dogs})$ were compared with a group of healthy dogs $(n=11$ dogs $)$. The inclusion criteria for CPSS were increased fasting plasma ammonia concentration, abnormal ammonia tolerance test (peak ammonia $\geq 150 \mu \mathrm{mol} / \mathrm{l}$ plasma) and ultrasonographic visualization of a small liver and a congenital portosystemic shunt with a diameter as wide as the portal vein trunk. The presence of the shunt was further confirmed with surgery, during which a wedge liver biopsy was taken and immediately put in liquid nitrogen and stored at $-70^{\circ} \mathrm{C}$, until analysis. In CPSS there is no portal hypertension. The inclusion criteria for PPVH were the visualization of a small liver with ultrasonography, presence of multiple small acquired portosystemic collaterals due to portal hypertension, and an abnormal ammonia tolerance test (peak ammonia $\geq 150 \mu \mathrm{mol} / \mathrm{l}$ plasma). Liver tissue of dogs with PPVH was obtained under local anaesthesia by ultrasound-guided biopsy with a true cut 16G biopsy needle. Two biopsies were immediately immersed in liquid nitrogen, and stored at $-70^{\circ} \mathrm{C}$, until analysis. The healthy control dogs were age-matched, and had AP, ALT, and fasting bile acids in plasma within the reference range. Ultrasonographically the control dog livers had a normal size, shape, and structure, and there were no histological abnormalities in stained histological sections.

\section{Histological grading of fibrosis}

Liver samples were fixed in $10 \%$ buffered formalin and routinely embedded in paraffin. Sections $(4 \mu \mathrm{m})$ were stained with haematoxylin-eosin, the Van Gieson stain, and the reticulin stain according to Gordon and Sweet. Histologically, the presence of fibrosis was evaluated semi-quantitatively (absent, slight, moderate, or marked) as well as with respect to its localization. Fibrosis scoring was performed according to Scheuer, a defined scoring method for fibrosis in hepatitis. The slides were independently examined by one certified veterinary pathologist.

\section{RNA isolation and reverse-transcription polymerase chain reaction}

Total cellular RNA was isolated from each frozen canine liver tissue in duplicate, using the RNeasy Mini Kit (Qiagen, Leusden, The Netherlands) according to the manufacturer's instructions. The RNA samples were treated with Dnase-I (Qiagen Rnase-free DNase kit). In total $3 \mu \mathrm{g}$ of RNA was incubated with poly(dT) primers at $42^{\circ} \mathrm{C}$ for 45 min, in a $60 \mu \mathrm{l}$ reaction volume, using the Reverse Tran- 
Table I: Nucleotide Sequences of Dog-Specific Primers for Real-Time Q-PCR.

\begin{tabular}{|c|c|c|c|c|c|}
\hline Gene & Primer & Sequence (5'-3') & ${ }^{\circ} \mathbf{C}$ & $\begin{array}{l}\text { Product } \\
\text { size (bp) }\end{array}$ & $\begin{array}{c}\text { Accession } \\
\text { number }\end{array}$ \\
\hline \multirow[t]{2}{*}{ GAPDH } & Forward & TGT CCC CAC CCC CAA TGT ATC & 58 & 100 & AB038240 \\
\hline & Reversed & CTC CGA TGC CTG CTT CAC TAC CTT & & & \\
\hline \multirow[t]{2}{*}{ HPRT } & Forward & AGC TTG CTG GTG AAA AGG AC & 56 & 100 & $\underline{\mathrm{L} 77488} / \underline{\mathrm{L} 77489}$ \\
\hline & Reversed & TTA TAG TCA AGG GCA TAT CC & & & \\
\hline \multirow[t]{2}{*}{ HGF } & Forward & AAA GGA GAT GAG AAA CGC AAA CAG & 58 & 92 & BDI05535 \\
\hline & Reversed & GGC CTA GCA AGC TTC AGT AAT ACC & & & \\
\hline \multirow[t]{2}{*}{ c-MET } & Forward & TGT GCT GTG AAA TCC CTG AAT AGA AATC & 59 & 112 & $\underline{A B|| 8945}$ \\
\hline & Reversed & CCA AGA GTG AGA GTA CGT TTG GAT GAC & & & \\
\hline \multirow[t]{2}{*}{ TGF $\alpha$} & Forward & CCG CCT TGG TGG TGG TCT CC & 63 & 136 & $\underline{A Y 458143}$ \\
\hline & Reversed & AGG GCG CTG GGC TTC TCG T & & & \\
\hline \multirow[t]{2}{*}{ HGF activator } & Forward & ACA CAG ACG TTT GGC ATC GAG AAG TAT & 60 & 128 & AY458142 \\
\hline & Reversed & AAA CTG GAG CGG ATG GCA CAG & & & \\
\hline \multirow[t]{2}{*}{ p27kip } & Forward & CGG AGG GAC GCC AAA CAG G & 60 & 90 & AY455798 \\
\hline & Reversed & GTC CCG GGT CAA CTC TTC GTG & & & \\
\hline \multirow[t]{2}{*}{ TGF- $\beta$ I } & Forward & CAA GGA TCT GGG CTG GAA GTG GA & 66 & 113 & $\underline{\mathrm{L} 34956}$ \\
\hline & Reversed & CCA GGA CCT TGC TGT ACT GCG TGT & & & \\
\hline \multirow[t]{2}{*}{ TGF- $\beta$ I R I } & Forward & CAG TCA CCG AGA CCA CAG ACA AAG T & 59 & 101 & AY455799 \\
\hline & Reversed & TGA AGA TGG TGC ACA AAC AAA TGG & & & \\
\hline \multirow[t]{2}{*}{ TGF- $\beta$ I R II } & Forward & GAC CTG CTG CCT GTG TGA CTT TG & 61 & 116 & AY455800 \\
\hline & Reversed & GGA CTT CGG GAG CCA TGT ATC TTG & & & \\
\hline \multirow[t]{2}{*}{ UPA } & Forward & CTG GGG AGA TGA AGT TTG AGG TGG & 64.5 & 105 & AY45580I \\
\hline & Reversed & TGG AAC GGA TCT TCA GCA AGG C & & & \\
\hline \multirow[t]{2}{*}{$\mathrm{BCl}-2$} & Forward & TGG AGA GCG TCA ACC GGG AGA TGT & 61 & 87 & $\underline{A B|16| 45}$ \\
\hline & Reversed & AGG TGT GCA GAT GCC GGT TCA GGT & & & \\
\hline \multirow[t]{2}{*}{ Fas Ligand } & Forward & GGG GTC AGT CCT GCA ACA ACA A & 54 & 94 & AY603042 \\
\hline & Reversed & ATC TTC CCC TCC ATC AGC ATC AG & & & \\
\hline \multirow[t]{2}{*}{ Caspase-3 } & Forward & ATC ACT GAA GAT GGA TGG GTT GGT & 58 & 140 & AB085580 \\
\hline & Reversed & GAA AGG AGC ATG TTC TGA AGT AGC ACT & & & \\
\hline \multirow[t]{2}{*}{$\mathrm{HIFI} \alpha$} & Forward & TTA CGT TCC TTC GAT CAG TTG TCA & 61 & 106 & AY455802 \\
\hline & Reversed & GAG GAG GTT CTT GCA TTG GAG TC & & & \\
\hline \multirow[t]{2}{*}{ Collagen I } & Forward & GTG TGT ACA GAA CGG CCT CA & 61 & 111 & $\underline{\text { AF056303 }}$ \\
\hline & Reversed & TCG CAA ATC ACG TCA TCG & & & \\
\hline \multirow[t]{2}{*}{ Collagen III } & Forward & ATA GAG GCT TTG ATG GAC GAA & 65 & 134 & AB042266 \\
\hline & Reversed & CCT CGC TCA CCA GGA GC & & & \\
\hline \multirow[t]{2}{*}{ Collagen IV } & Forward & CAC AGC CAG ACA ACA GAT GC & 67 & 151 & $\underline{\mathrm{U} 07888}$ \\
\hline & Reversed & GCA TGG TAC TGA AGC GAC G & & & \\
\hline \multirow[t]{2}{*}{ Fibronectin } & Forward & AGG TTG TTA CCA TGG GCA & 61 & 91 & $\underline{\mathrm{U}} 2106$ \\
\hline & Reversed & GCA TAA TGG GAA ACC GTG TAG & & & \\
\hline
\end{tabular}

scription System from Promega (Promega Benelux, Leiden, The Netherlands).

\section{Quantitative measurements of the mRNA levels of HGF, TGF- $\beta$ I, and other related signaling molecules}

Q-PCR based on the high affinity double-stranded DNAbinding dye SYBR ${ }^{\circledast}$ green I (BMA, Rockland, ME) was performed in triplicate in a spectrofluorimetric thermal iCy$\operatorname{cler}^{\circledast}$ (BioRad, Veenendaal, The Netherlands). Data were collected and analyzed with the provided application software. For each Q-PCR, $2 \mu \mathrm{l}$ (of the 2 times diluted stock) of cDNA was used in a reaction volume of $50 \mu \mathrm{l}$ containing $1 \times$ manufacturer's buffer, $2 \mathrm{mM} \mathrm{MgCl}{ }_{2}, 0.5 \times \mathrm{SYBR}^{\otimes}$ green I, $200 \mu \mathrm{M}$ dNTP's, $20 \mathrm{pmol}$ of both primers, 1.25 units of AmpliTaq Gold (Applied Biosystems, Nieuwerk- erk a/d IJssel, The Netherlands), on 96-well iCycler iQ plates (BioRad). Primer pairs, depicted in Table 1, were designed using PrimerSelect software (DNASTAR Inc., Madison, WI). All PCR protocols included a 5-minute polymerase activation step and continued for 40 cycles at $95^{\circ} \mathrm{C}$ denaturation for $20 \mathrm{sec}$, annealing for $30 \mathrm{sec}$ and elongation at $72^{\circ} \mathrm{C}$ for $30 \mathrm{sec}$ with a final extension for 5 min at $72^{\circ} \mathrm{C}$. Annealing temperatures were optimized at various levels ranging from $56^{\circ} \mathrm{C}$ till $67^{\circ} \mathrm{C}$ (Table 1). Melt curves (iCycler, BioRad), agarose gel electrophoresis, and standard sequencing procedures were used to examine each sample for purity and specificity (ABI PRISM 3100 Genetic Analyser, Applied Biosystems). Standard curves constructed by plotting the relative starting amount versus threshold cycles were generated using serial 4-fold dilu- 
Table 2: Used antibodies in Western blot experiments.

\begin{tabular}{|c|c|c|c|c|c|}
\hline Antigen & Product Size (kDa) & Dilution & Manufacturer & $\begin{array}{l}\text { Secondary } \\
\text { antibody }\end{array}$ & Dilution \\
\hline HGF & 82 & $\mathrm{I}: 100$ & Neomarkers & Anti-mouse HRP & $1: 20,000$ \\
\hline $\begin{array}{c}\text { P-c-MET (Tyr I230/I 234/ } \\
\text { I 235) }\end{array}$ & 145 & $\mathrm{I}: 750$ & Abcam & Anti-rabbit HRP & $1: 20,000$ \\
\hline c-MET & 145 & $\mathrm{I}: 750$ & Sigma & Anti-goat HRP & $1: 20,000$ \\
\hline p-PKB (Thr 308) & 60 & I:I,000 & Cell-Signaling & Anti-mouse HRP & $1: 20,000$ \\
\hline PKB & 60 & $1: 250$ & BD Biosciences & Anti-mouse HRP & $\mathrm{I}: 20,000$ \\
\hline P-STAT3 (Ser 727) & 86 & $1: 1,000$ & Cell Signalling & Anti-rabbit HRP & $\mathrm{I}: 20,000$ \\
\hline STAT3 & 86 & $1: 2,500$ & BD Biosciences & Anti-rabbit HRP & $1: 20,000$ \\
\hline p-Erkl/2 (Thr 202/Tyr 204) & $42 / 44$ & $1: 1,500$ & Cell Signalling & Anti-rabbit HRP & $\mathrm{I}: 20,000$ \\
\hline ERKI/2 & $42 / 44$ & $1: 1,000$ & Cell Signalling & Anti-rabbit HRP & $1: 20,000$ \\
\hline TGF- $\beta$ I & 25 & $1: 1,000$ & Abcam & Anti-rabbit HRP & $\mathrm{I}: 20,000$ \\
\hline p-Smad2 (Ser 465/467) & 58 & $1: 2,000$ & Cell-Signaling & Anti-rabbit HRP & $\mathrm{I}: 20,000$ \\
\hline Smad2 & 58 & $\mathrm{I}: 500$ & BD Biosciences & Anti-mouse HRP & $\mathrm{I}: 20,000$ \\
\hline Collagen I & $95 / 210$ & $1: 500$ & Calbiochem & Anti-mouse HRP & $1: 20,000$ \\
\hline Caspase-3 & $34 / 20 / 18$ & $1: 1,000$ & Calbiochem & Anti-rabbit HRP & $\mathrm{I}: 20,000$ \\
\hline Beta-actin (pan Ab-5) & 42 & $1: 2,000$ & Neomarkers & Anti-mouse HRP & $\mathrm{I}: 20,000$ \\
\hline
\end{tabular}

tions of pooled cDNA fractions from both healthy and diseased liver tissues. The amplification efficiency, E (\%) $=\left(10^{(1 /-s)}-1\right) * 100(\mathrm{~s}=$ slope $)$, of each standard curve was determined and appeared to be $>95 \%$, and $<105 \%$, over a wide dynamic range. For each experimental sample, the amount of the gene of interest, and of the endogenous references glyceraldehyde-3-phosphate dehydrogenase (GAPDH) and hypoxanthine phosphoribosyl transferase (HPRT) were determined from the appropriate standard curve in autonomous experiments. If relative amounts of GAPDH and HPRT were constant for a sample, data were considered valid and the average amount was included in the study (data not shown). Results were normalized according to the average amount of the endogenous references. The normalized values were divided by the normalized values of the calibrator (healthy group) to generate relative expression levels [40].

\section{Statistical analysis}

A Kolmogorov-Smirnov test was performed to establish a normal distribution and a Levene's test for the homogeneity of variances. All samples included in this study were normally distributed and homogeneous in variance. The statistical significance of differences between diseased and control animals was determined by using the Student's ttest. A p-value $<0.05$ was considered statistically significant. Analysis was performed using SPSS software (SPSS Benelux BV, Gorinchem, The Netherlands).

\section{Western blot analysis}

Used antibodies are described in Table 2. For Western blot analysis $30 \mathrm{mg}$ of liver tissue from at least six samples of each group ( $n=6$ dogs per group, randomly chosen from original group) were pooled and analyzed. Liver tissues were homogenized in RIPA buffer containing 1\% Igepal, $0.6 \mathrm{mM}$ phenylmethylsulfonyl-fluoride, $17 \mu \mathrm{g} / \mathrm{ml}$ aprotinine, and $1 \mathrm{mM}$ sodium-orthovanadate (Sigma chemical Co., Zwijndrecht, The Netherlands). Protein concentrations were obtained using a Lowry-based assay (DC Protein Assay, BioRad). Twenty $\mu \mathrm{g}$ of protein of the supernatant was denatured for $3 \mathrm{~min}$ at $95^{\circ} \mathrm{C}$ and electroforesed on $7.5 \%$ Tris- $\mathrm{HCl}$ polyacrylamide gels (BioRad) and the proteins were transferred onto Hybond-C Extra Nitrocellulose membranes (Amersham Biosciences Europe, Roosendaal, The Netherlands) using a Mini Trans-Blot ${ }^{\oplus}$ Cell blot-apparatus (BioRad). Immunodetection was based on an ECL Western blot analysis system, performed according to the manufacturer's instructions (Amersham Biosciences Europe). The membranes were incubated with 4\% ECL blocking solution in TBS for 1 hour under gentle shaking. The incubation of the primary antibody was performed at $4{ }^{\circ} \mathrm{C}$ over-night for all antibodies (see Table 2) in TBS with 0.1\% Tween-20 (Boom B.V., Meppel, The Netherlands). After washing, the membranes were incubated with their respective horseradish peroxidase-conjugated secondary antibody (R\&D systems, Europe Ltd., Abingdon, UK) at room temperature for $1 \mathrm{~h}$ and exposed to Kodak BioMax Light-1 films (Sigma chemical Co.). Densitometric analysis of immunoreactive bands was performed with a Gel Doc 2000 system coupled to the Quantity One 4.3.0 Software (BioRad).

\section{Competing interests}

The author(s) declare that they have no competing interests. 


\section{Authors' contributions}

BS performed most Q-PCR measurements and wrote the manuscript. LP participated in the setup of Q-PCR measurements and helped to draft the manuscript. TI histochemically examined samples described in this manuscript. BA helped perform the0 Western blot experiments. JIJ histochemically examined samples described in this manuscript. FS helped collect all samples. JR participated in the study design and helped to draft the initial manuscript. All authors read and approved the final manuscript.

\section{Acknowledgements}

The authors are indebted to Dr. Alexandra Pietersen, Dr. Bernard Roelen, and Dr. Peter ten Dijke for their invaluable advice.

\section{References}

I. Guyon R, Lorentzen TD, Hitte C, Kim L, Cadieu E, Parker HG, Quignon $P$, Lowe JK, Renier C, Gelfenbeyn B, Vignaux F, DeFrance $H B$, Gloux S, Mahairas GG, Andre C, Galibert F, Ostrander EA: A I-Mb resolution radiation hybrid map of the canine genome. Proc Natl Acad Sci U S A 2003, 100:5296-530I.

2. Murray CP, Yoo SJ, Babyn PS: Congenital extrahepatic portosystemic shunts. Pediatr Radio 2003, 33:6I4-620.

3. van den Ingh TS, Rothuizen J, Meyer HP: Circulatory disorder of the liver in dogs and cats. Vet $Q$ 1995, 17:70-76.

4. van den Ingh TS, Rothuizen J, Meyer HP: Portal Hypertension associated with primary hypoplasia of the hepatic portal vein in dogs. Vet $\operatorname{Rec} 1995$, I37:424-427.

5. Michalopoulos KM, DeFrances MC: Liver regeneration. Science 1997, 276:60-66.

6. Trusolino L, Comoglio PM: Scatter-factor and semaphorin receptors: cell signalling for invasive growth. Nat Rev Cancer 2002, 2:289-300.

7. Fausto N: Liver regeneration. J Hepatol 2000:|9-3|.

8. Funakoshi $H$, Nakamura $T$ : Hepatocyte growth factor: from diagnosis to clinical applications. Clin Chim Acta 2003, 327:I-23.

9. Scheid MP, Woodgett JR: Unravelling the activation mechanisms of protein kinase B/Akt. FEBS Lett 2003, 546: I08-I I 2.

10. Coffer PJ, Jin J, Woodgett JR: Protein kinase B (c-Akt): a multifunctional mediator of phosphatidylinositol 3-kinase activation. Biochem J 1998, 335:1-13.

II. Paumelle R, Tulasne D, Kherrouche Z, Plaza S, Leroy C, Reveneau S, Vandenbunder B, Fafeur V, Tulashe D, Reveneau S: Hepatocyte growth factor/scatter factor activates the ETSI transcription factor by a RAS-RAF-MEK-ERK signaling pathway. Oncogene 2002, 21:2309-2319.

12. Boccaccio C, Ando M, Tamagnone L, Bardelli A, Michieli P, Battistini C, Comoglio PM: Induction of epithelial tubules by growth factor HGF depends on the STAT pathway. Nature 1998, 391:285-288.

13. Derynck R, Akhurst RJ, Balmain A: TGF- $\beta$ signaling in tumor suppression and cancer progression. Nature Genet 200I, 29:117-129.

14. Piek E, Heldin CA, ten Dijke P: Specificity, diversity, and regulation in TGF- $\beta$ superfamily signalling. FASEB J 1999 , 13:2105-2124.

15. Aihara $\mathrm{Y}$, Kasuya $\mathrm{H}$, Onda $\mathrm{H}$, Hori T, Takeda J: Quantitative analysis of gene expressions related to inflammation in canine spastic artery after subarachnoid hemorrhage. Stroke 200I, 32:212-217.

16. Massague J: How cells read TGF-beta signals. Nat Rev Mol Cell Biol 2000, I: 169-178.

17. Hengartner MO: The biochemistry of apoptosis. Nature 2000, 407:770-776.

18. Norman JT, Clark IM, Garcia PL: Hypoxia promotes fibrogenesis in human renal fibroblasts. Kidney Int 2000, 58:235I-2366.

19. Vandesompele J, De Preter K, Pattyn F, Poppe B, Van Roy N, De Paepe A, Speleman F: Accurate normalization of real-time quantitative RT-PCR data by geometric averaging of multi- ple internal control genes. Genome Biol 2002 , 3:research0034.I-research0034.II.

20. Schmidt C, Bladt F, Goedecke S, Brinkmann V, Zschiesche W, Sharpe M, Gherardi E, Birchmeier C: Scatter factor/hepatocyte growth factor is essential for liver development. Nature 1995, 373:699-702.

21. La Rosa S, Uccella S, Capella C, Erba S, Sessa F: Localization of Hepatocyte Growth Factor and Its Receptor met in Endocrine Cells and Related Tumors of the Gut and Pancreas: An Immunohistochemical Study. Endocr Pathol 2000, I I:3 I 5-329.

22. Barthelemy C, Henderson CE, Pettmann B: Foxo3a induces motoneuron death through the Fas pathway in cooperation with JNK. BMC Neurosci 2004, 5:48.

23. Chandramohan $\mathrm{V}$, Jeay S, Pianetti S, Sonenshein GE: Reciprocal control of Forkhead box $\mathrm{O} 3 \mathrm{a}$ and c-Myc via the phosphatidylinositol 3-kinase pathway coordinately regulates p27Kip I levels. J Immunol 2004, I 72:5522-5527.

24. Hanada $M$, Feng J, Hemmings BA: Structure, regulation and function of PKB/AKT - a major therapeutic target. Biochim Biophys Acta 2004, 1697:3-16.

25. Nakagami H, Morishita R, Yamamoto K, Taniyama Y, Aoki M, Matsumoto K, Nakamura T, Kaneda $Y$, Horiuchi M, Ogihara T: Mitogenic and antiapoptotic actions of hepatocyte growth factor through ERK, STAT3, and AKT in endothelial cells. Hypertension 200I, 37:581-586.

26. Diez-Marques L, Ortega-Velazquez R, Langa C, Rodriguez-Barbero A, Lopez-Novoa JM, Lamas S, Bernabeu C: Expression of endoglin in human mesangial cells: modulation of extracellular matrix synthesis. Biochim Biophys Acta 2002, 1587:36-44.

27. Zhu HJ, Burgess AW: Regulation of transforming growth factor-beta signaling. Mol Cell Biol Res Commun 200I, 4:32I-330.

28. Tsukada S, Parsons C], Rippe RA: Mechanisms of liver fibrosis. Clin Chim Act in press.

29. Liu C, Gaca MD, Swenson ES, Vellucci VF, Reiss M, Wells RG: Smads 2 and 3 are differentially activated by transforming growth factor-beta (TGF-beta) in quiescent and activated hepatic stellate cells. Constitutive nuclear localization of Smads in activated cells is TGF-beta-independent. I Biol Chem 2003, 278: $11721-11728$.

30. Kondou H, Mushiake S, Etani Y, Miyoshi Y, Michigami T, Ozono K: A blocking peptide for transforming growth factor-betal activation prevents hepatic fibrosis in vivo. J Hepatol 2003, 39:742-748.

31. Kataoka H, Miyata S, Uchinokura S, Itoh H: Roles of hepatocyte growth factor (HGF) activator and HGF activator inhibitor in the pericellular activation of HGF/scatter factor. Cancer Metastasis Rev 2003, 22:223-236.

32. Wang HT, Chen S, Wang J, Ou QJ, Liu C, Zheng SS, Deng MH, Liu $X P$ : Expression of growth hormone receptor and its mRNA in hepatic cirrhosis. World J Gastroenterol 2003, 9:765-770.

33. Kosai K, Matsumoto K, Funakoshi H, Nakamura T: Hepatocyte growth factor prevents endotoxin-induced lethal hepatic failure in mice. Hepatology 1999, 30:15I-159.

34. Yasuda H, Imai E, Shiota A, Fujise N, Morinaga T, Higashio K: Antifibrogenic effect of a deletion variant of hepatocyte growth factor on liver fibrosis in rats. Hepatology 1996, 24:636-642.

35. Ueki T, Kaneda Y, Tsutsui H, Nakanishi K, Sawa Y, Morishita R, Matsumoto K, Nakamura T, Takahashi H, Okamoto E, Fujimoto J: Hepatocyte growth factor gene therapy of liver cirrhosis in rats. Nat Med 1 999, 5:226-230.

36. Matsuda $Y$, Matsumoto K, Yamada A, Ichida T, Asakura H, Komoriya Y, Nishiyama E, Nakamura T: Preventive and therapeutic effects in rats of hepatocyte growth factor infusion on liver fibrosis/ cirrhosis. Hepatology 1997, 26:8I-89.

37. Ohara K, Kusano M: Anti-transforming growth factor-betal antibody improves survival rate following partial hepatectomy in cirrhotic rats. Hepatol Res 2002, 24:174.

38. Nakamura T, Sakata R, Ueno T, Sata M, Ueno H: Inhibition of transforming growth factor $\beta$ prevents progression of liver fibrosis and enhanced hepatocyte regeneration in dimethylnitrosamine-treated rats. Hepatology 2000, 32:247-255.

39. Sato M, Kakubari M, Kawamura M, Sugimoto J, Matsumoto K, Ishii T: The decrease in total collagen fibers in the liver by hepatocyte growth factor after formation of cirrhosis induced by thioacetamide. Biochem Pharmacol 2000, 59:681-690. 
40. Kimura Y, Leung PS, Kenny TP, van de Water J, Nishioka M, Giraud AS, Neuberger J, Benson G, Kaul R, Ansari AA, Coppel RL, Gershwin ME: Differential expression of intestinal trefoil factor in biliary epithelial cells of primary biliary cirrhosis. Hepatology 2002 ,

Publish with Bio Med Central and every scientist can read your work free of charge

"BioMed Central will be the most significant development for disseminating the results of biomedical research in our lifetime. " Sir Paul Nurse, Cancer Research UK

Your research papers will be:

- available free of charge to the entire biomedical community

- peer reviewed and published immediately upon acceptance

- cited in PubMed and archived on PubMed Central

- yours - you keep the copyright

Submit your manuscript here:

http://www.biomedcentral.com/info/publishing_adv.asp
BioMedcentral 